Article

\title{
Sentinel-2 Satellites Provide Near-Real Time Evaluation of Catastrophic Floods in the West Mediterranean
}

\author{
Isabel Caballero * ${ }^{\mathbb{D}}$, Javier Ruiz and Gabriel Navarro \\ Instituto de Ciencias Marinas de Andalucía (ICMAN), Consejo Superior de Investigaciones Científicas (CSIC), \\ Avenida República Saharaui, 11519 Puerto Real, Spain; javier.ruiz@icman.csic.es (J.R.); \\ gabriel.navarro@icman.csic.es (G.N.) \\ * Correspondence: isabel.caballero@icman.csic.es
}

Received: 18 October 2019; Accepted: 25 November 2019; Published: 27 November 2019

\begin{abstract}
Flooding is among the most common natural disasters in our planet and one of the main causes of economic and human life loss worldwide. Evidence suggests the increase of floods at European scale with the Mediterranean coast being critically vulnerable to this risk. The devastating event in the West Mediterranean during the second week of September 2019 is a clear case of this risk crystallization, when a record-breaking flood (locally called the "Cold Drop" (Gota Fría)) has swollen into a catastrophe to the southeast of Spain surpassing previous all-time records. By using a straightforward approach with the Sentinel-2 twin satellites from the Copernicus Programme and the ACOLITE atmospheric correction processor, an initial approximation of the delineated flooded zones, including agriculture and urban areas, was accomplished in quasi-real time. The robust and flexible approach requires no ancillary data for rapid implementation. A composite of pre- and post-flood images was obtained to identify change detection and mask water pixels. Sentinel-2 identifies not only impacts on land but also on water ecosystem and its services, providing information on water quality deterioration and concentration of suspended matter in highly sensitive environments. Subsequent water quality deterioration occurred in large portions of Mar Menor, the largest coastal lagoon in the Mediterranean. The present study demonstrates the potentials brought by the free and open-data policy of Sentinel-2, a valuable source of rapid synoptic spatio-temporal information at the local or regional scale to support scientists, managers, stakeholders, and society in general during and after the emergency.
\end{abstract}

Keywords: Copernicus Programme; ACOLITE; flooding; quasi-real time monitoring; inundation mapping; suspended matter; Spain

\section{Introduction}

Flooding is among the most common natural disasters in our planet and one of the main causes of economic and human life loss worldwide [1]. During the period 1980-2013, flood losses exceeded $\$ 1$ trillion globally and resulted in ca. 220,000 fatalities [2]. In addition, the frequency and scale of floods are likely to increase in next decades not only due to climate-related extremes and natural hazards but also because ongoing socio-economic development [3]. Several studies of river floods and storms in Europe suggested that the observed increases in losses were principally due to economic wealth, increases in populations, and developments in hazard-prone areas, but the increase in heavy precipitation in some regions of Europe may have also influenced these [4,5]. Human activity is undoubtedly contributing to an increase in the likelihood and adverse impacts of extreme flood events. The population inhabiting risky zones is growing and, at the same time, construction in flood plains 
and inappropriate river management is reducing rivers capacity to absorb floodwaters. Coastal areas are also at risk of flooding; according to the European Environment Agency State of the Environment and Eurosion, the total value of European economic assets located within $500 \mathrm{~m}$ of the coastline, including agricultural, beaches, land and industrial facilities, is currently estimated at $€ 500$ to $€ 1000$ billion [6]. In 2007, the Floods Directive for the assessment and management of flood risk was adopted by the European Commission (EC), and worth mentioning is the operative monitoring by the EC Copernicus Emergency Management Service (Copernicus EMS) [7]. In addition to social and economic damage, floods may cause severe environmental impacts, as well as reduce biodiversity and destroy wetland areas. In Europe, a climatic-change signal in flood discharges has been demonstrated in relation to changes in the timing of floods within the year [8]. However, the regional scale diagnose of these events is hampered by lack of a coherent signal mainly due to the restricted spatial coverage and density of hydrometric stations [9]. A recent study analysing co-occurring heavy precipitation and high sea level (compound flooding) in Europe showed that the Mediterranean coasts are at present experiencing the highest compound flooding probability, being critically vulnerable to this risk [10].

The devastating event in the west Mediterranean during the second week of September 2019 is a clear case of this risk crystallization, when a record-breaking flood (locally called the "Cold Drop" (Gota Fría)) has swollen into a catastrophe to the southeast of Spain (Figure 1). This weather event typical of the fall season, where a sudden fall in temperatures appears along the east coast caused by the arrival of very cold polar air [11], is already being described as one of the worst. Wide areas have dramatically broken historical records of daily rainfall and flash floods, created chaos on roads, cut public transport, blocked roads, destroyed homes, closed schools, collapsed rivers, and caused six human fatalities in Valencia, Alicante, Murcia, and eastern Andalusia (Figure 1). These provinces remained on red alert during several days. Spain's weather agency continued to issue severe weather warnings during various days as storms bringing torrential rain in excess of $300 \mathrm{~L} / \mathrm{m}^{2}$, hail, winds up to $100 \mathrm{~km} / \mathrm{h}$, huge waves, and flood risk swept across the Southeast of the Iberian Peninsula. A clear example of the extreme rain event could be observed at a meteorological station in the Orihuela region (red star in Figure 1), where the daily precipitation rate during 12-13 September surpassed that of previous years (Figure 2). The government informed the material and economic damages caused by this extraordinary meteorological phenomenon are still unquantifiable owing to its magnitude, declaring the region a disaster area. On 13 September, the authorities reported that the Segura River had burst its banks in Orihuela, a town of around 80,000 residents in Alicante province. Thousands of residents from different municipalities were evacuated due to the extreme weather conditions of one of the most spectacular floods in Spain, where current catastrophic flooding has far surpassed previous all-time records in the West Mediterranean.

Understanding the spatiotemporal and physical characteristics of risk drivers (exposure, hazard, and vulnerability) is needed in order to implement effective flood mitigation measures [12]. As a means of emergency response after a flooding or inland inundation, flood mapping helps to identify the extent of the event on a large scale as well as the affected infrastructure such as roads and settlements and impaired regions of interest such as agricultural areas. This information can be used by disaster management agencies and other stakeholders to undertake the rescue in affected areas, coordinating appropriate recovery activities and prevention measures for possible upcoming events. Currently, the catastrophic impacts of flooding can be evaluated by means of remote sensing technologies, which provide a unique source of data for the implementation of European Union (EU) directives [13]. Remote sensing technologies are one of the most widely used platforms for emergency management and extended area mapping. Satellite images can be applied to assess the extent of flooded areas and their impact on human, economic, environment, and infrastructure offering a synoptic view of large areas, frequent observations, and historical archives. Several studies have focused on obtaining information using remote sensing imagery with the application of different methodologies [14-18]. Particularly, when optical satellite data are available before and after a flooding event, identification of flooded regions and water quality deterioration in the coastal areas would be much easier by means of change 
detection approaches. These approaches frequently require the application of pre-and post-flood image pairs to distinguish pixels that have been modified from non-water to water between image dates and have been implemented using post classification image differencing [19]. Whereas these techniques can offer useful and accurate results, the combined challenges of storm-related cloud cover and low temporal resolution remain important limitations. For this evaluation, high temporal and fine spatial resolution images are required in order to comprehensively generate accurate maps.
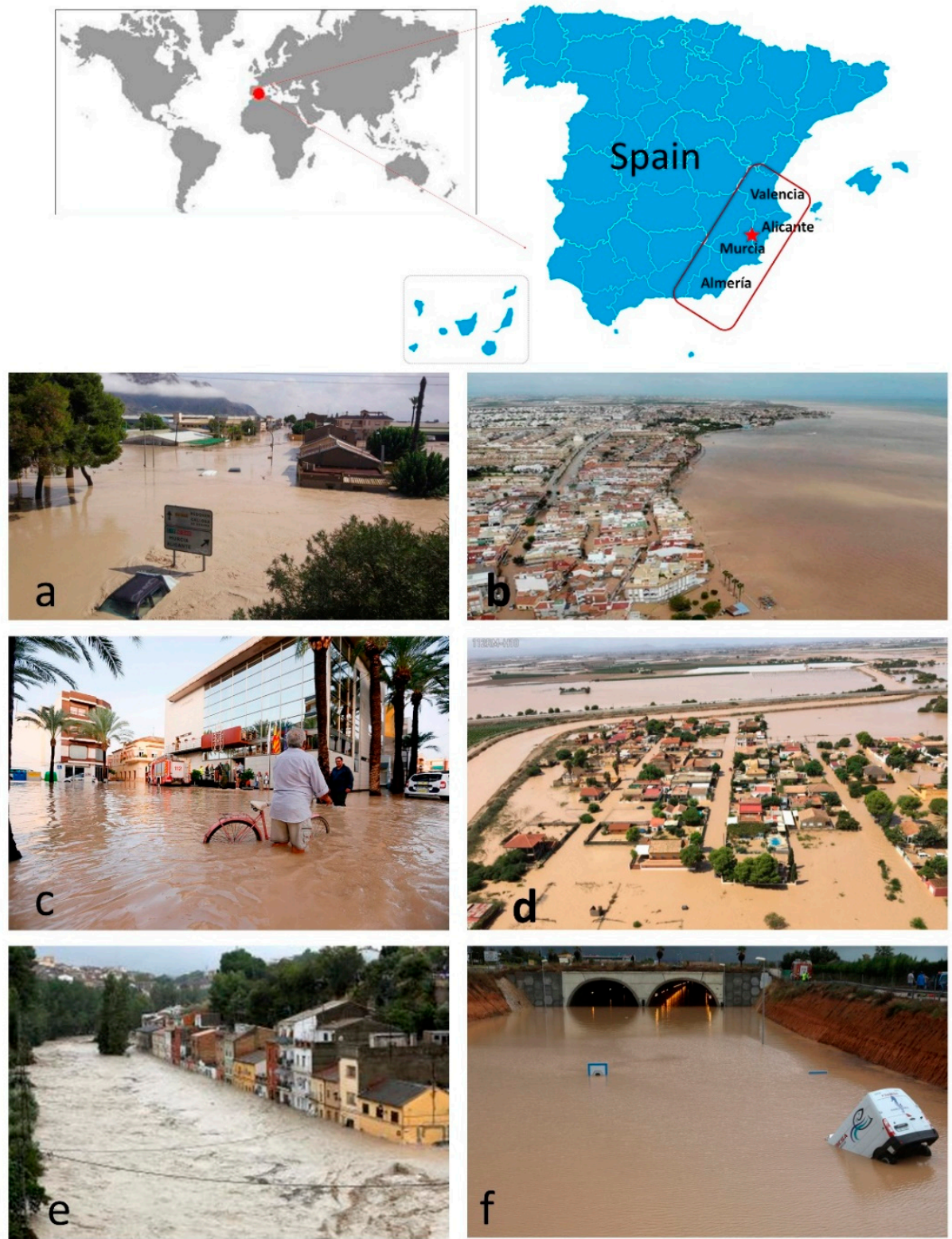

Figure 1. Location of the Spanish regions impacted by the flooding in September 2019 from south to north: Almeria, Murcia, Alicante, and Valencia. The red star corresponds to the location of the meteorological station in Orihuela (Figure 2). Photos showing the record-breaking flooding during the Cold Drop (Gota Fría) in Alicante (a) and (c), Murcia (b) and (d), and Valencia (e), and (f) during 11-14 September 2019. The photos are courtesy of Levante, Efe, España Diario, REUTERS, and El Confidencial. 

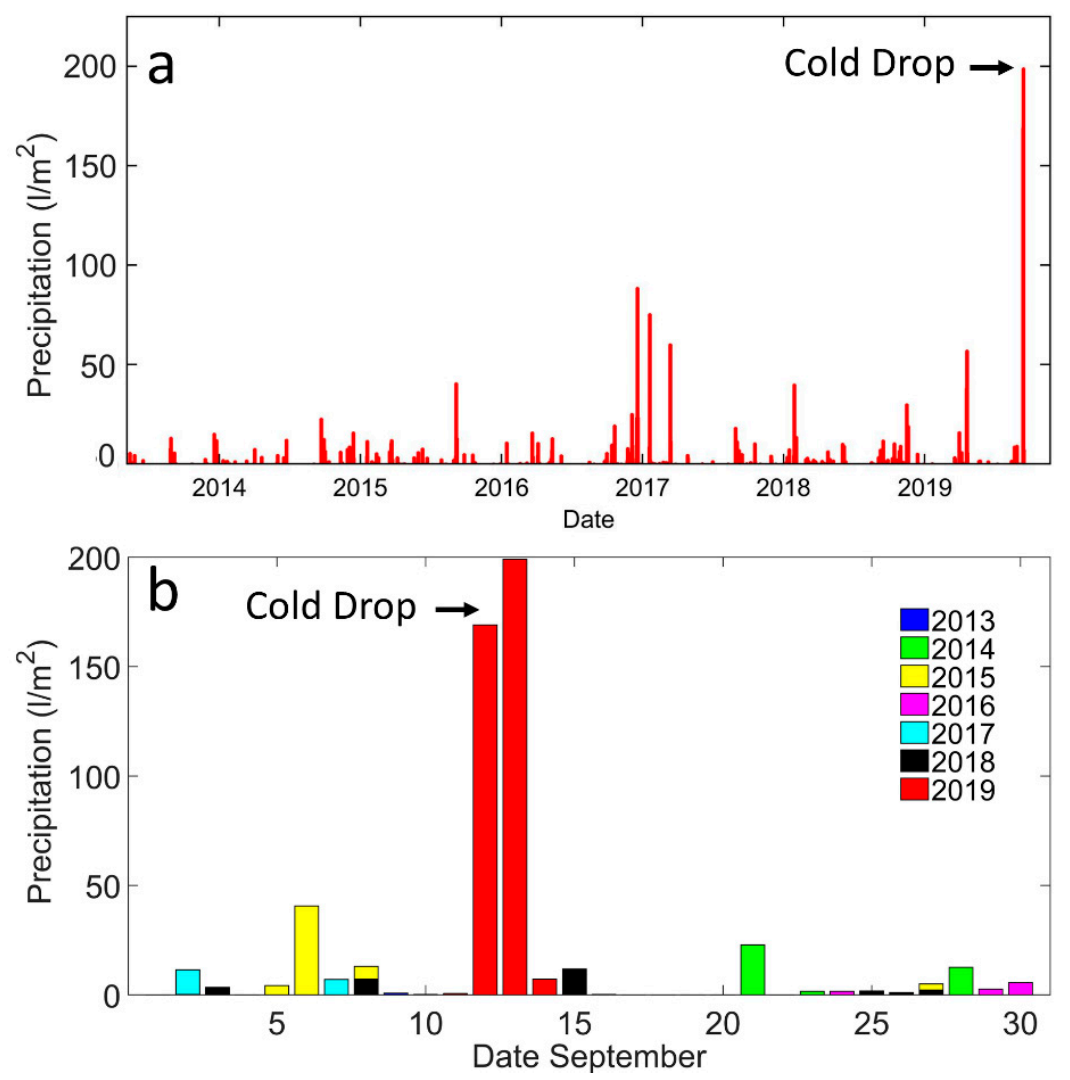

Figure 2. (a) Historical daily rainfall (litre per square metre, $\mathrm{L} / \mathrm{m}^{2}$ ) in a meteorological station in the Orihuela region (Alicante, red star in Figure 1) and (b) daily precipitation during September 2013-2019, where the extreme precipitation during the Cold Drop event on 12-13 September 2019 is highlighted in red.

In this regard, the European Space Agency (ESA), in partnership with the EC, is developing a new family of missions called the Sentinels for the operational needs of the Copernicus Programme. Each Sentinel is based on a constellation of two twin satellites to fulfil revisit and coverage requirements, providing robust datasets for Earth Observation Services, beginning a new era in disaster monitoring and emergency management [20]. These missions carry a range of technologies, such as multi-spectral imaging and radar instruments for ocean, land, and atmospheric monitoring, and are designed to deliver the wealth of data and imagery that are central to improve the management of the environment, safeguarding lives every day. Specifically, the Copernicus Sentinel-2 mission comprises a constellation of two polar-orbiting satellites placed in the same sun-synchronous orbit, phased at $180^{\circ}$ from each other. It aims at monitoring variability in land and water surface conditions to provide imagery of vegetation, soil, water cover, and inland waterways. The 5-day revisit of the pair of Multi Spectral Imagers (MSI) onboard Sentinel-2 with $10 \mathrm{~m}$ spatial resolution in visible bands, combined with freely available data, is unprecedented, providing new insights into the observation of nearly any coastal place on Earth [21]. This enables for new endeavours in monitoring, change detection, and mapping of coastal zones.

In the present contribution, a demonstration of a satellite-based tool as an effective solution to address and delimit flood-affected areas and to evaluate the effects of the flood on the water quality (suspended sediments) of the Spanish coastal regions following the catastrophic flood during September 2019 was accomplished. A straightforward approach has been applied using a recently released software suited for atmospheric correction (ACOLITE processor) with Sentinel-2A/B images before and after the event, indicating the potentials brought by the twin satellite's wide coverage and high revisit for change detection. The findings are an example of addressing near-real time flooding 
monitoring in large areas providing a preliminary valuable source of synoptic information to support managers, scientists, stakeholders, and society during and after the emergency.

\section{Materials and Methods}

In this study, the Sentinel-2A and 2B twin polar-orbiting satellites were used. Both Multispectral Instruments (MSI) on-board are now operational: Sentinel-2A was launched on 23 June 2015 and Sentinel-2B followed on 7 March 2017. A free, full, and open data policy has been adopted by the EU for the Copernicus Programme, which foresees access by all users to the Copernicus Sentinels core products. The radiometric, spectral, and spatial characteristics of the bands used in this study are specified in the User Handbook [21]. A temporal examination provided Level-1C Sentinel-2 images that were typically geo-located within two pixels of each other $(20 \mathrm{~m})$ which is within the stated quality requirements for absolute geo-location [22]. Sentinel-2 Level 1 datasets (zone 30, sub-tile SXG and SXH) were downloaded from the ESA official website Copernicus Open Access Hub [23]. The Copernicus Services Data Hub is an access to Copernicus Sentinels data dedicated to Copernicus Services and European Institutions. Copernicus Sentinel-2 data are systematically processed to L1C products and made available online between 2 and $12 \mathrm{~h}$ from sensing (on average, $7 \mathrm{~h}$ after sensing) in the Copernicus Open Access Hub and Copernicus Services Data Hub. Only images with low cloud coverage $(<20 \%$ over the region of study) were considered and downloading time was generally around $0.5 \mathrm{~h}$. At least two images with the same orbit track and the same coverage are required for change detection, namely, the reference image (pre-event) and the target image (co-event), respectively. The reference image was selected as the latest available image prior to the event with minimum cloud coverage. The scenes were selected carefully with two Sentinel-2A/B satellite images before (19 August 2B, 3 September 2A) and two scene-captures during or immediately following (13 September 2A, 18 September 2B) the event (Figure 2).

A straightforward approach has been accomplished by means of the ACOLITE software developed by the Royal Belgian Institute of Natural Sciences RBINS (version 20190326.0). ACOLITE bundles the processing software and atmospheric correction algorithms implemented at RBINS for aquatic applications of Sentinel-2 (A/B) and Landsat (5/7/8) satellite information. ACOLITE performs the atmospheric correction and can provide several parameters derived from water reflectance. ACOLITE was originally developed in IDL (2014-2017) and has been translated into Python (2018-2019). The Dark Spectrum Fitting (DSF) atmospheric correction was used [24]. This model was originally implemented for water applications of fine resolution metre-scale optical satellites but proved capacities for use with MSI due to their finer spectral coverage [25]. The DSF computes atmospheric path reflectance based on multiple dark targets in the scene or subscene, with no a priori defined dark band. For each band, the darkest object is estimated from the offset fit to the first thousand pixels in the histogram and a "dark spectrum". A Continental or Maritime aerosol model is chosen based on the lowest RMSD between the observed reflectance and the retrieved path reflectance for the two closest fitting bands. The settings selected for the DSF were a tiled path reflectance option, which divides the full scene in approximately $6 \times 6 \mathrm{~km}$ tiles and interpolates retrieved path reflectance. In this study, optional image-based sun glint correction of the surface reflectance was also incorporated. Total time for ACOLITE processing was $\sim 2.5 \mathrm{~h}$ (see workflow diagram in Figure 3). Processing speed and time were associated to a Windows 10 Pro desktop machine with Inter(R) Core ${ }^{\mathrm{TM}} \mathrm{i7.}$

MSI has spectral bands at different spatial resolutions, 10, 20, and $60 \mathrm{~m}$ and ACOLITE converts internally the bands to the same (user-specified) resolution. For bands at lower resolution than the processing resolution, values are replicated by nearest neighbour resampling, i.e., no new pixel values are computed, and for bands at higher resolution, pixels are spatially mean averaged. By default, the $10 \mathrm{~m}$ grid is used, which means the values from the 20 and $60 \mathrm{~m}$ bands are replicated 4 and 36 times to form a $10 \mathrm{~m}$ grid. In this study, ACOLITE products resampled to $10 \mathrm{~m}$ pixel size corresponded to Remote Sensing Reflectance (Rrs, 1/sr) in all visible and Near-Infrared (NIR) bands. The concentration of total suspended material (TSM, $\mathrm{g} / \mathrm{m}^{3}$ ) was also calculated using a standard approach [26], a model 
which is suitable for any ocean colour sensor. Theory indicates that use of a single band, if chosen adequately, offers a robust and TSM-sensitive algorithm. Retrieving suspended matter in optically shallow water requires the use of spectral bands that have limited depth penetration in order to avoid substantial interference from the bottom but at the same time are sensitive to turbidity. Red bands are useful for estimation of suspended matter but can have a strong bottom signal in shallow waters [27]. The absorption by water increases rapidly from red to the "red edge" NIR (700-780 nm). This absorption limits the light received from the bottom, while still returning light scattered from materials in the water. In this sense, the red-edge NIR band $704 \mathrm{~nm}$ has sufficient water absorption to be a good compromise between detecting turbidity with limited detection of the bottom, so it was selected for the suspended matter algorithm [26] within the ACOLITE processor. Several studies have already indicated these red-edge spectral bands are appropriate for turbidity or suspended solids monitoring in optically shallow regions $[27,28]$.

Non-water pixels were masked on the maps using a combination of thresholds and spectral tests within ACOLITE. Masking is performed after the atmospheric correction, using the retrieved surface reflectance. Rrsmin and Rrsmax represent the minimum and maximum reflectance in the sensor bands, respectively. The data were masked if any one of the four spectral tests used was true: "Bright" spectral test, "NIR peak" spectral test, "Non-water" spectral test, and "White" spectral test (see more details on [24]):

"Bright" spectral test: Water pixels have a maximum reflectance much less than $20 \%$, and hence pixels should be masked where:

$$
R r s_{\max }>0.2
$$

"NIR peak" spectral test: Water pixels have a visible band reflectance higher than NIR reflectance (except for extremely turbid waters), and hence, pixels should be masked where:

$$
\operatorname{Max}\left(\operatorname{Rrs}_{\text {blue }}, \operatorname{Rrs}_{\text {green }}, \operatorname{Rr} s_{\text {red }}\right)<\operatorname{Rr} s_{\text {NIR }}
$$

"Non-water" spectral test: The NIR to red reflectance ratio is limited to a given ratio for water pixels (except for extremely turbid waters), and hence, pixels should be masked where:

$$
\begin{gathered}
\frac{R r s_{N I R}}{R r s_{\text {red }}}>0.9 \\
R r s_{\text {NIR }}>0.05
\end{gathered}
$$

"White" spectral test: Water pixels typically have a large spectral variability in the visible and NIR, and hence, pixels should be masked where:

$$
\frac{R r s_{\max }-R r s_{\min }}{R r s_{\max }}<0.2
$$

Based on the later and while computing thresholds, the two satellite imageries on 13 and 18 September after change detection were clarified into damaged and un-damaged areas. These data were processed within few hours, saving on time and resources and enabling the near-real time quantification of the flooded areas and water quality issues (see workflow diagram in Figure 3). Moreover, information on the historical daily rainfall of a meteorological station in Orihuela, Alicante (red star in Figure 1, 38 $04^{\prime} 04^{\prime \prime} \mathrm{N}, 0^{\circ} 58^{\prime} 53^{\prime \prime} \mathrm{W}$ ) was obtained from Aemet Open Data [29]. 


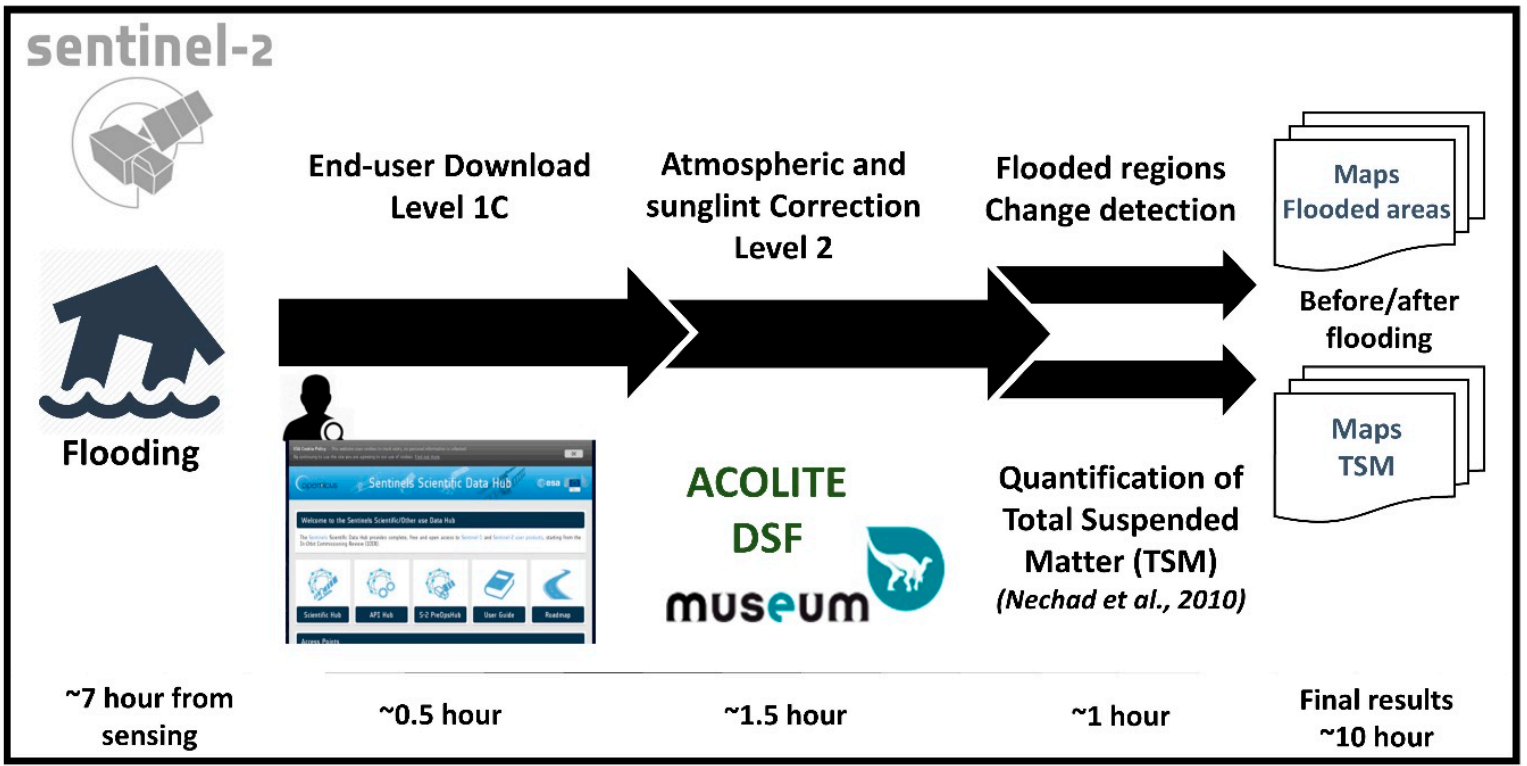

Figure 3. Diagram with workflow and time processing for each step using Sentinel-2 images and ACOLITE processor.

\section{Results}

The Sentinel-2 images as true colour composite Red-green-blue from the EO Browser [30] at $10 \mathrm{~m}$ spatial resolution show the before on 3 September 2019 (Figure 4a) and after on 13 September 2019 (Figure $4 \mathrm{~b}$ ) of the flooding event in Murcia province (Spain). The affected and non-affected zones were delineated, resulting in a flooded area of 1307 ha (Figure 5) over the Region of Interest on 13 September (ROI detailed in Figure 4b). This phenomenon has damaged the cultivated lands, mainly in Los Alcázares region (Figure $4 \mathrm{~b}$ ), where the exceptional rainfall caused widespread flooding and damage to agricultural lands, much of them farmed under agri-environment agreements. While flooding in winter is a common event in this region, flooding in late summer or early autumn (associated to the Gota Fría) is unusual and much more damaging. The information retrieved can be used to evaluate the impacts on flooded areas and help inform strategies to deal with changes in flood risk in areas of agricultural and environmental interest.

Moreover, Sentinel-2 identifies not only impacts on land but also on water ecosystem and its services. Due to the large quantity of sediments brought by the flood, the affected regions show an extreme increase of total suspended material and severe turbidity levels, visible in the RGB image (Figure $4 b$ ), leading to a contamination and deterioration of the rivers and the coastal adjacent region (Figure 2b). Large portions of Mar Menor (the largest coastal lagoon in the Mediterranean) showed up to $200 \mathrm{mg} / \mathrm{m}^{3}$ of suspended solids on 13 September (Figure $4 \mathrm{~d}$ ) compared to the standard situation ten days before on 3 September with minimum concentration $<10 \mathrm{mg} / \mathrm{m}^{3}$ (Figure $4 \mathrm{c}$ ). There were no in situ data to validate the TSM algorithm, but realistic information can be observed for the mapping of suspended matter using the TSM model [26] with the $704 \mathrm{~nm}$ band. A recent study has confirmed that Sentinel-2 red-edge bands achieved good accuracies when compared with suspended solid concentrations [31], in addition to the red or NIR bands [32,33]. One of the main advantages of Sentinel-2 over Landsat-8 is the inclusion of these three red-edge and NIR bands, allowing for the determination of chlorophyll in turbid and productive waters and the retrieval of turbidity or suspended particulate matter concentration, even in narrow inlets and ports, providing an invaluable dataset for several scientific and management purposes [34]. The TSM model was not able to perform accurately over the extremely turbid region close to the coast and part of the turbid intrusion was masked out by ACOLITE processor (similar results were found using other TSM algorithms within ACOLITE software). 

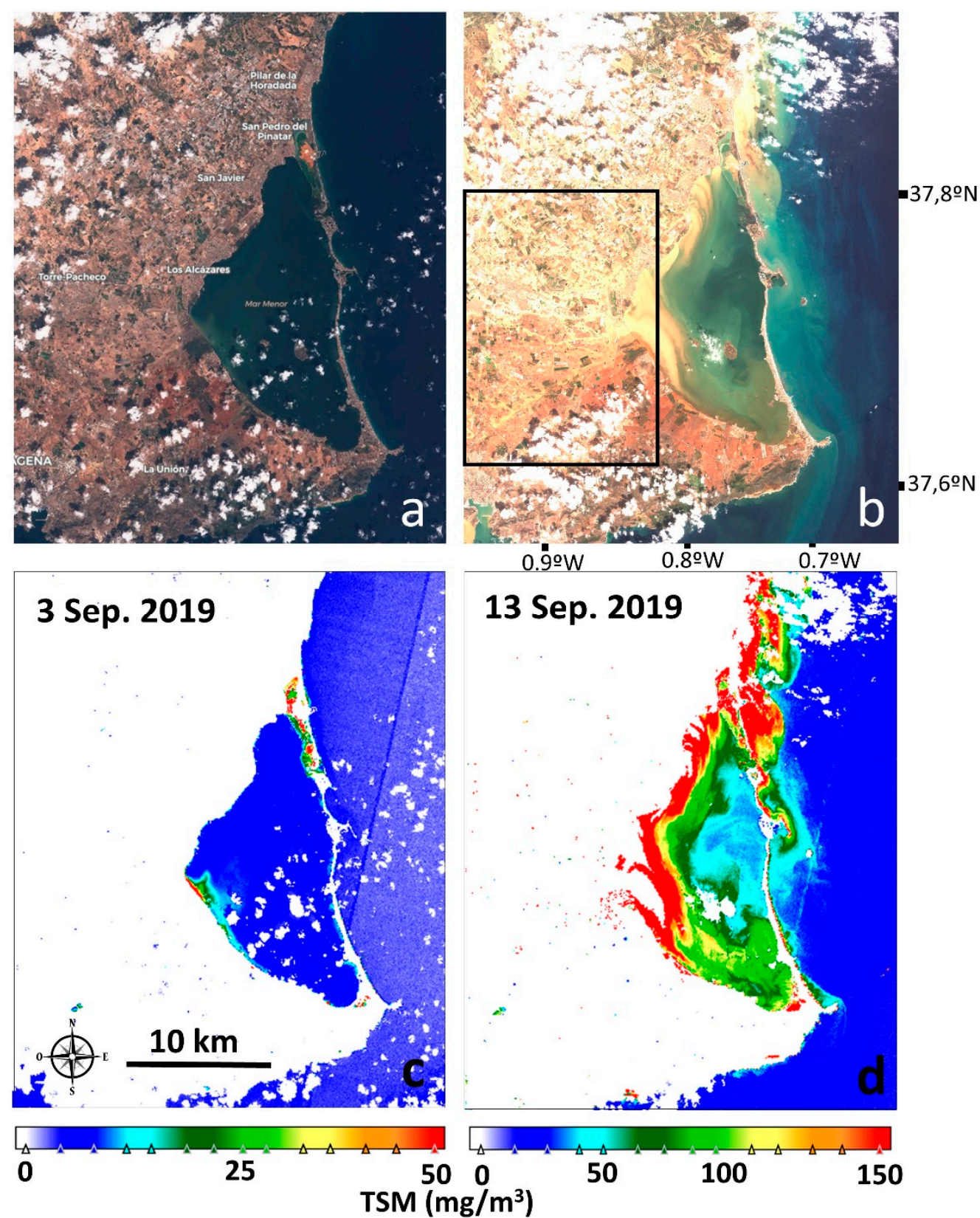

Figure 4. Sentinel-2 images at $10 \mathrm{~m}$ spatial resolution as true colour composite (red-green-blue) from the EOBroswer showing the (a) before (3 September 2019) and (b) after (13 September 2019) of the flooding event in Murcia province (Spain). The high concentration of suspended material (TSM, $\mathrm{mg} / \mathrm{m}^{3}$ ) in Mar Menor can be observed in the map (d) on 13 September with TSS $>200 \mathrm{mg} / \mathrm{m}^{3}$ compared to the normal situation (c) on 3 September 2019 with minimum concentration $\left(10 \mathrm{mg} / \mathrm{m}^{3}\right)$. White areas correspond to land, clouds, or cloud shadows masked after ACOLITE. Black rectangle shows the Region of Interest (ROI) for flooded area calculation. The TSS scales for each scene are different. 


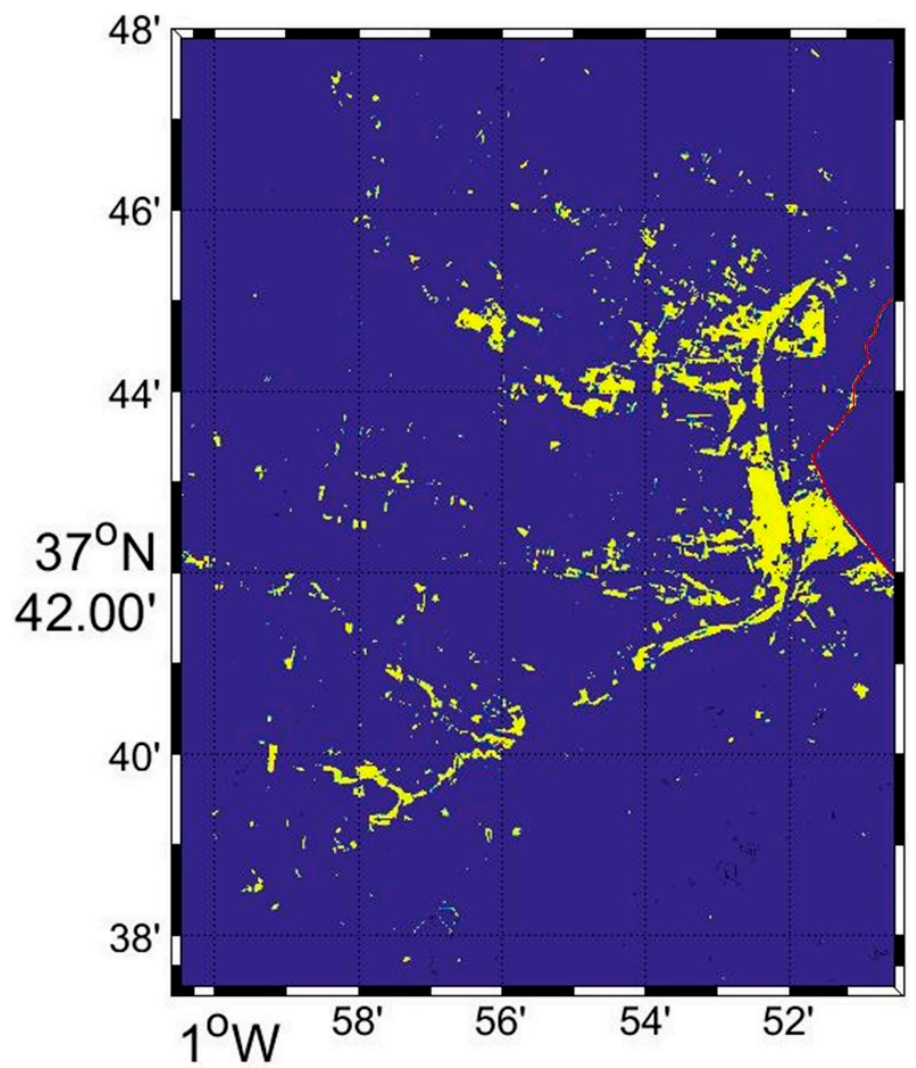

Figure 5. The flood-affected areas (yellow) in Murcia on 13 September 2019 within the Region of Interest (ROI) defined in Figure $4 \mathrm{~b}$ (black rectangle). The red line represents the coastal line.

In the Dolores region (Alicante), pre (19 August 2019, Figure 6) and post (18 September 2019, Figure $6 \mathrm{~b}$ ) Sentinel-2 false colour composite (near infrared-green-blue) from the EO Browser indicated the affected regions, with an estimated flooded area of 3150 ha on 18 Sep (Figure 7) within the ROI (rectangle in Figure 6b). This scene corresponds to some days following the event, thus some flood areas cloud not be well documented (scene 13 September over Alicante region has severe cloud contamination). The delineation of the flooded zones, including agriculture and urban areas impacted as well as identification of the affected infrastructures can be observed in the false colour image (Figure $6 \mathrm{~b}$ ). Water quality in reservoirs servicing human consumption and agriculture was also deteriorated as can be observed in the turbidity plume associated to the Segura River on 18 Sep with concentration of suspended solids up to $150 \mathrm{mg} / \mathrm{m}^{3}$ (Figure 6d) compared to the normal situation on 19 August 2019 with minimum concentration $<10 \mathrm{mg} / \mathrm{m}^{3}$ (Figure 6c). 

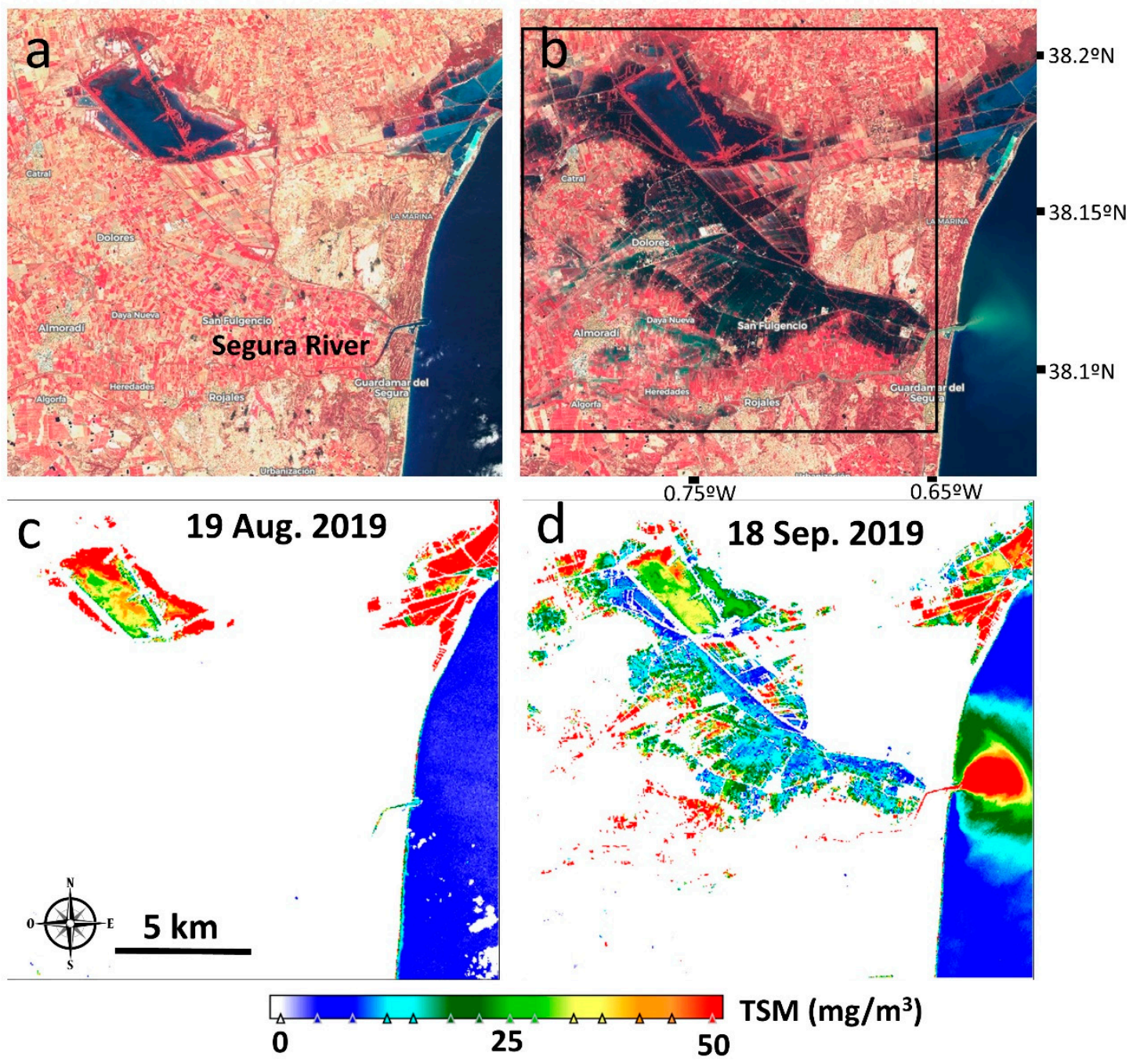

Figure 6. Sentinel-2 images at $10 \mathrm{~m}$ spatial resolution as false colour composites (near infrared-green-blue) from the EO Browser showing the (a) before (19 August 2019) and (b) after (18 September 2019) of the flooding event in the Dolores region, Alicante province (Spain). The high concentration of suspended material (TSM, mg/m $\mathrm{m}^{3}$ ) in the Segura River coastal region $>50 \mathrm{mg} / \mathrm{m}^{3}$ can be observed in the map (d) on 18 September compared to the normal situation (c) on 19 August 2019 with minimum concentration $\left(<10 \mathrm{mg} / \mathrm{m}^{3}\right)$. White areas correspond to land, clouds or clouds shadows masked after ACOLITE. Black rectangle shows the Region of Interest (ROI) for flooded area calculation. 


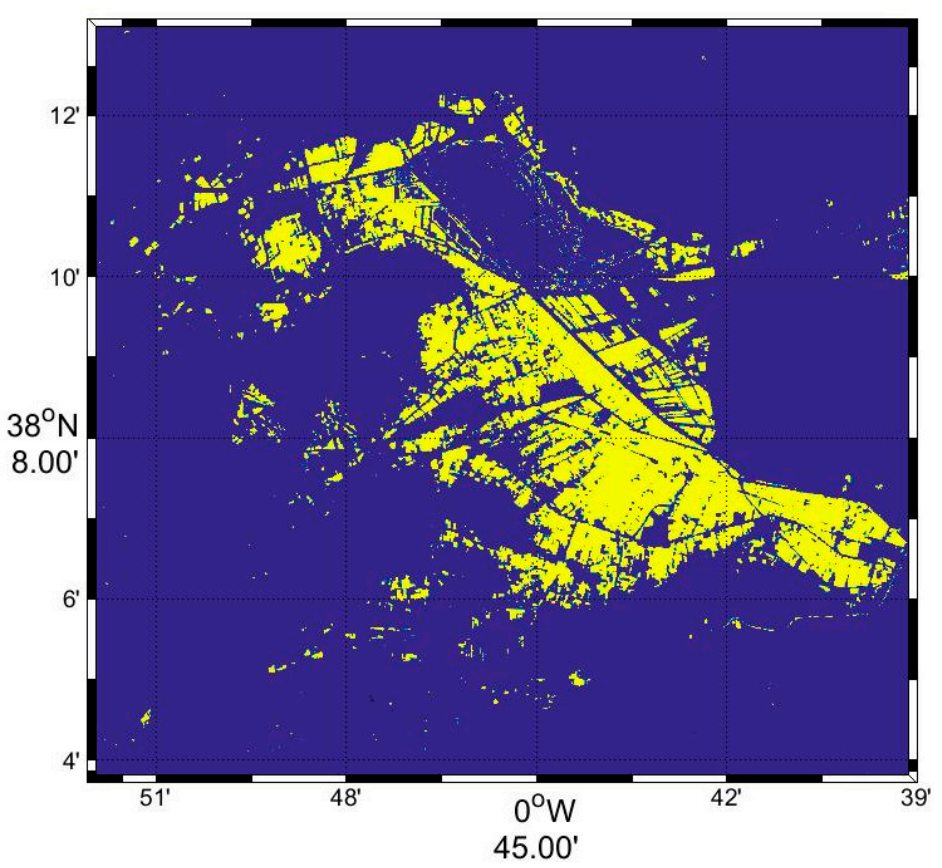

Figure 7. The flood-affected areas (yellow) in Alicante on 18 September 2019 within the Region of Interest (ROI) defined in Figure $6 \mathrm{~b}$ (black rectangle).

\section{Discussion}

In this study, an operative procedure after the flooding event was applied to automatically map flooded areas and suspended matter from multispectral Sentinel-2 images with a novel ACOLITE processor based on the DSF model. Up to our knowledge, it is the first time ACOLITE tool has been tested for quick assessment of flooded-affected areas. This framework is proposed as a way to rapidly obtain key preliminary information while potentially automating the image processing, allowing accurate initial approximation maps. The ability to retrieve products for quasi-real-time monitoring is proved, with final products obtained on average after $10 \mathrm{~h}$ from sensing: $7 \mathrm{~h}$ to process and made available the data by Copernicus, $0.5 \mathrm{~h}$ for downloading, and $2.5 \mathrm{~h}$ for ACOLITE processing and generation of final maps (Figure 3). The promising employment of advanced software such as ACOLITE combined with the fine-scale Sentinel-2 satellite imagery to optimize mapping in short times might benefit operational and scientific monitoring and management, especially in data-poor regions of the world.

Subsequent hypoxic and other undesirable consequences occurred in the highly sensitive environment of Mar Menor after the flooding. The intrusion of turbid waters to the Mediterranean (Figure 4) also played its role in the massive mortality of bluefin tuna and seahorses landing in the beaches during the event. In addition, during the first week of October 2019, the lack of oxygen killed thousands of fish and shellfish in this basin, and the Minister of Environment in the Murcia Government confirmed that the water quality in the lagoon was much worse than before the Cold Drop. The information provided by Sentinel- 2 might assist the coordination of efforts by all bodies involved in the administration of the Mar Menor in order to resolve the problems exacerbated by the Cold Drop.

The method establishes a plausible high-quality strategy with sufficient sensitivity to support interannual and pre-post hazards, which may benefit change detection analysis from multiple images to discriminate variability. Change detection plays a crucial role in flood monitoring using remote sensing data, while the selection of a reference image is crucial in order to obtain an accurate thematic map. We needed to acquire suitable cloud-free scenes without sun-glint and other noise-inducing environmental variables, but this work was not straightforward. However, the high revisit time of 
Sentinel-2 provided increased likelihood of obtaining cloud-free scenes delivering time-sensitive data. The availability of the Sentinel-2A/B images each 5 days made possible to select pre/post-flooding or co-occurring images. It is also important to highlight that this study benefited from the availability of the post-flood image captured days after the extreme flooding (18 September) in Dolores region, when many inundated areas were still saturated at the surface.

The flooded-affected areas estimated with Sentinel-2 data collected for post-event assessment have been visually validated with datasets from Copernicus [7] as well as based on dwellers information. Activation of the Copernicus Emergency Management Service (EMS) provided mapping products to support emergency management activities immediately following a disaster, in this case screened to identify flood events with available clear sky post-event images using the very fine resolution WorldView-2 and Pléiades-1A satellites. Visual assessment against EMS data indicated close agreement with scoured riverbanks and high-water marks, and the performance in this study is consistent and comparable to standard approaches focused on the Copernicus Programme. Similar flooded affected zones have been delineated with Sentinel-2 in Dolores region, although differences might appear due to the lower resolution of MSI $(10 \mathrm{~m})$ compared to the very fine resolution of both WorldView-2 and Pléiades-1A $(\sim 2 \mathrm{~m})$. A more exhaustive assessment of the flooding mapping could be considered through quantitative comparison with independent data, such as Copernicus Emergency maps, for a more comprehensive evaluation of methodology and performance. However, the aim of this research was to explore the suitability of the atmospheric correction method applied to Sentinel-2 data for quick mapping of flooded areas and suspended matter. Potential timely uses of the retrieved information can be the basis for civil protection or for prompt delimitation of areas or districts hit by the flood. This information could be considered without requiring very high quantitative performances of the proposed methodology in terms of accuracy in flooded area delimitation or in the mapping of the real levels of suspended matter in the coastal waters. The application of the ACOLITE processor for coastal mapping has been recently reported in other studies [32,33].

Sentinel-2 might provide a way to use other satellites more effectively, assisting as a reference data set that can be used to inform mapping conducted with the various commercial very high-resolution sensors such as the World-View fleet [35] or the novel CubeSats from Planet [36]. On the other scale, Landsat has a four-decade record of Thematic Mapper and has been shown useful even with $30 \mathrm{~m}$ pixels [37,38]. Comparisons of Sentinel-2 with Landsat-8 may ultimately lead to results that could expand the utility of the entire Landsat data record for change detection. The development of new cloud environments and standardizing methodologies (e.g.,: Google Earth Engine or the Coastal Thematic Exploitation Platform Coastal-TEP by ESA) may aid in the routine application of Sentinel-2. Accordingly, for further avenues of research with Sentinel-2, we intend to upscale the study results to more environments as well as implement the approach in cloud-based computing platforms such as Google Earth Engine.

Recent studies have already suggested the potential of Sentinel-2 for automated mapping of flooded areas [39]. The state of the art of the methods for water detection from multispectral images is well described in the literature with approaches based on the Normalized Difference Water Index-NDWI [40], the modified NDWI [41], the Water Ratio Index [42], or the Water Index [43]. From an end user perspective, ACOLITE allows a quick, easy, and automated processing to generate preliminary information for change detection based on a well-described thresholding approach. Compared to flood mapping with a single image, change detection-based methods have an advantage in masking out the permanent water bodies (rivers, lakes) and some water look-alike objects through the identification of inundated soil and land from post-flood imagery [44]. The robust and flexible approach was able to identify flood-related water pre-existing water bodies in Dolores (Alicante province). The flooding maps based on Sentinel-2 data may be operative as a preliminary emergency map, as it allows an accurate initial approximation of flooded-affected areas and water quality issues. Additionally, this information might be useful for defining the economic losses for the insurance sector and evaluating 
public compensation schemes [45], as this region of the Mediterranean is extremely vulnerable to climate change impacts [10].

Generally, Synthetic Aperture Radar (SAR) sensors have emerged as the main source of operational techniques for mapping flood extent and flood-prone areas by planning emergency response agencies $[46,47]$. SAR tools provide advantages to monitor flooding as they have unique capabilities compared with optical data; radar can work at night and with clouds due to their all-weather capabilities, so the use of radar images has increased considerably [48,49]. In this work, it is demonstrated that Sentinel-2A/B 5-day revisit, its rapid acquisition time, and the methodology adapted provided a robust product for emergency services of flood mapping and immediate damage assessment in disaster monitoring. Moreover, the straightforward nature of the strategy and its independence from ancillary training data makes it applicable and accessible for a wide variety of stakeholders, managers, and end users, especially in data-poor or remote areas. The Mar Menor is suffering several human pressures, such as sediment and nutrient inputs from agriculture and other activities, so implementation of operational strategies to monitor its evolution is critical to protect its fragile natural ecosystem [50]. In this regard, the open data policy and long-term mission commitment of Sentinel-2 opens future promising time series evaluation over years and even decades that can be an important tool to provide crucial missing information at the local or regional scale in a rapid and non-intrusive manner.

\section{Conclusions}

It is demonstrated that, in the event of a natural disaster, as the recent catastrophic flooding event occurred in Spain during the second week of September 2019, the Sentinel-2 fleet is a valuable rapid-response source of synoptic spatio-temporal information, and its benefit has been proven here. With their fine spatial and high temporal resolutions, these twin open-source satellites, particularly when coupled, have the potential to generate rapid information of the affected flooded parcels and of the water quality, data that is key for both the local government body as well as for the habitats to better assist policies plans and to deliver compensations based on it. This scheme can be established operationally for monitoring procedures bringing a considerable benefit to support managers, stakeholders and society during the emergency. On a longer term, the scientific rigor of the derived diagnoses can guide research and help to assist in objectively accounting losses and compensation needs as well as to design mitigation plans for future events. They can also provide a solid base of information to determine whether or not these events have a climatic component as well as to aid in the establishment of flood warning systems. It is an exciting avenue for future research how these services provided by science to society can be delivered with the Sentinel-2 mission, allowing new endeavours in high-resolution mapping and monitoring which will significantly increase the availability of crucial information after flooding events.

Author Contributions: Conceptualization, I.C., J.R., and G.N.; methodology, I.C.; formal analysis, I.C.; investigation, I.C., J.R., and G.N.; Writing—original draft preparation, I.C., J.R., and G.N.

Funding: This research was funded by the Spanish Ministry of Science, Innovation and Universities (MCIU), the State Research Agency (AEI), and the European Regional Development Fund (ERDF) in the frame of the Sen2Coast Project "Improved assessment of algorithms for bathymetry and water quality parameters with Sentinel-2A/B high-resolution satellites for advancement of coastal applications" (RTI2018-098784-J-I00).

Acknowledgments: We acknowledge the European Commission and the European Space Agency for the Sentinel-2 datasets. The authors acknowledge the three anonymous reviewers, whose comments helped to improve this manuscript.

Conflicts of Interest: The authors declare no conflict of interest. The funders had no role in the design of the study; in the collection, analyses, or interpretation of data; in the writing of the manuscript; or in the decision to publish the results. 


\section{References}

1. European Commission. Directive 2007/60/EC of the European Parliament and of the Council of 23 October 2007 on the assessment and management of flood risks. Off. J. Eur. Union L. 2007, 288, 27-34.

2. ReNatCat. SERVICE Database Munich RE. Munich. 2014. Available online: https://www.munichre.com/en/ solutions/for-industry-clients/natcatservice.html (accessed on 3 October 2019).

3. Jongman, B.; Ward, P.J.; Aerts, J.C. Global exposure to river and coastal flooding: Long term trends and changes. Glob. Environ. Change 2012, 22, 823-835. [CrossRef]

4. Barredo, J.I. Normalised flood losses in Europe: 1970-2006. Nat. Hazards Earth Syst. Sci. 2009, 9, 97-104. [CrossRef]

5. Feyen, L.; Dankers, R.; Bódis, K.; Salamon, P.; Barredo, J.I. Fluvial flood risk in Europe in present and future climates. Clim. Change 2012, 112, 47-62. [CrossRef]

6. Eurosion. Available online: http://www.eurosion.org/ (accessed on 25 September 2019).

7. European Commission Copernicus Emergency Management Service. Available online: http://emergency. copernicus.eu (accessed on 25 September 2019).

8. Blöschl, G.; Hall, J.; Parajka, J.; Perdigão, R.A.; Merz, B.; Arheimer, B.; Aronica, G.T.; Bilibashi, A.; Bonacci, O.; Borga, M. Changing climate shifts timing of European floods. Science 2017, 357, 588-590. [CrossRef]

9. Hall, J.; Arheimer, B.; Borga, M.; Brázdil, R.; Claps, P.; Kiss, A.; Llasat, M.C. Understanding flood regime changes in Europe: A state of the art assessment. Hydrol. Earth Syst. Sci. 2014, 18, 2735-2772. [CrossRef]

10. Bevacqua, E.; Maraun, D.; Vousdoukas, M.I.; Voukouvalas, E.; Vrac, M.; Mentaschi, L.; Widmann, M. Higher potential compound flood risk in Northern Europe under anthropogenic climate change. Sci. Adv. 2019, 5. [CrossRef]

11. Diez, J.J.; Esteban, M.D.; Silvestre, J.M. Understanding Extreme Spanish Coastal Flood Events. In EGU General Assembly Conference Abstracts; EGU: München, Germany, 2013; Volume 15, Available online: https: //ui.adsabs.harvard.edu/abs/2013EGUGA..15.1957D/abstract (accessed on 7 October 2019).

12. Tanoue, M.; Hirabayashi, Y.; Ikeuchi, H. Global-scale river flood vulnerability in the last 50 years. Sci. Rep. 2016, 6, 36021. [CrossRef]

13. Bresciani, M.; Stroppiana, D.; Odermatt, D.; Morabito, G.; Giardino, C. Assessing remotely sensed chlorophyll-a for the implementation of the Water Framework Directive in European perialpine lakes. Sci. Total Environ. 2011, 409, 3083-3091. [CrossRef]

14. Sanyal, J.; Lu, X.X. Application of remote sensing in flood management with special reference to monsoon Asia: A review. Nat. Hazards 2004, 33, 283-301. [CrossRef]

15. Joyce, K.E.; Belliss, S.E.; Samsonov, S.V.; McNeill, S.J.; Glassey, P.J. A review of the status of satellite remote sensing and image processing techniques for mapping natural hazards and disasters. Prog. Phys. Geogr. 2009, 33, 183-207. [CrossRef]

16. Schnebele, E.; Cervone, G. Improving remote sensing flood assessment using volunteered geographical data. Nat. Hazards Earth Syst. Sci. 2013, 13, 669-677. [CrossRef]

17. Li, Y.; Martinis, S.; Plank, S.; Ludwig, R. An automatic change detection approach for rapid flood mapping in Sentinel-1 SAR data. Int. J. Appl. Earth Obs. Geoinf. 2018, 73, 123-135. [CrossRef]

18. Ovando, A.; Martinez, J.M.; Tomasella, J.; Rodriguez, D.A.; von Randow, C. Multi-temporal flood mapping and satellite altimetry used to evaluate the flood dynamics of the Bolivian Amazon wetlands. Int. J. Appl. Earth Obs. Geoinf. 2018, 69, 27-40. [CrossRef]

19. Wang, Y. Using Landsat 7 TM data acquired days after a flood event to delineate the maximum flood extent on a coastal floodplain. Int. J. Remote Sens. 2004, 25, 959-974. [CrossRef]

20. Sentinel Constellation. Available online: https://sentinel.esa.int/web/sentinel/missions (accessed on 25 September 2019).

21. European Space Agency. Sentinel-2 User Handbook. ESA Standard Document Paris, France 2015. Available online: https://sentinel.esa.int/documents/247904/685211/Sentinel-2_User_Handbook (accessed on 1 October 2019).

22. European Space Agency. Sentinel-2 MSI Technical Guide 2017. Available online: https://earth.esa.int/web/ sentinel/technical-guides/sentinel-2-msi (accessed on 1 October 2019).

23. Sentinel's Scientific Data Hub. Available online: https://scihub.copernicus.eu/ (accessed on 19 September 2019). 
24. Vanhellemont, Q.; Ruddick, K. Atmospheric correction of metre-scale optical satellite data for inland and coastal water applications. Remote Sens. Environ. 2018, 216, 586-597. [CrossRef]

25. Vanhellemont, Q. Adaptation of the dark spectrum fitting atmospheric correction for aquatic applications of the Landsat and Sentinel-2 archives. Remote Sens. Environ. 2019, 225, 175-192. [CrossRef]

26. Nechad, B.; Ruddick, K.G.; Park, Y. Calibration and validation of a generic multisensor algorithm for mapping of total suspended matter in turbid waters. Remote Sens. Environ. 2010, 114, 854-866. [CrossRef]

27. International Ocean-Colour Coordinating Group (IOCCG). Remote Sensing of Ocean Colour in Coastal, and Other Optically-Complex, Waters; IOCCG: Dartmouth, NS, Canada, 2000.

28. Kutser, T.; Paavel, B.; Verpoorter, C.; Ligi, M.; Soomets, T.; Toming, K.; Casal, G. Remote sensing of black lakes and using $810 \mathrm{~nm}$ reflectance peak for retrieving water quality parameters of optically complex waters. Remote Sens. 2016, 8, 497. [CrossRef]

29. Aemet Open Data. Available online: https://datosclima.es (accessed on 27 September 2019).

30. EO Browser. Available online: https://www.sentinel-hub.com/explore/eobrowser (accessed on 23 September 2019).

31. Liu, H.; Li, Q.; Shi, T.; Hu, S.; Wu, G.; Zhou, Q. Application of sentinel 2 MSI images to retrieve suspended particulate matter concentrations in Poyang Lake. Remote Sens. 2017, 9, 761. [CrossRef]

32. Caballero, I.; Steinmetz, F.; Navarro, G. Evaluation of the first year of operational Sentinel-2A data for retrieval of suspended solids in medium-to high-turbidity waters. Remote Sens. 2018, 10, 982. [CrossRef]

33. Caballero, I.; Navarro, G. Retrieval of Suspended Solids from Landsat-8 and Sentinel-2: A Tool for Coastal Monitoring in Extremely Turbid Waters. In Proceedings of the IGARSS 2018-2018 IEEE International Geoscience and Remote Sensing Symposium 2018, Valencia, Spain, 22-27 July 2018; pp. 7874-7877. [CrossRef]

34. Vanhellemont, Q.; Ruddick, K. Acolite for Sentinel-2: Aquatic applications of MSI imagery. In Proceedings of the 2016 ESA Living Planet Symposium, Prague, Czech Republic, 9-13 May 2016.

35. DigitalGlobe. Available online: https://www.digitalglobe.com/company/ (accessed on 25 September 2019).

36. Planet Labs. Available online: https://www.planet.com/ (accessed on 28 September 2019).

37. Amarnath, G. An algorithm for rapid flood inundation mapping from optical data using a reflectance differencing technique. J. Flood Risk Manag. 2014, 7, 239-250. [CrossRef]

38. Chignell, S.; Anderson, R.; Evangelista, P.; Laituri, M.; Merritt, D. Multi-temporal independent component analysis and Landsat 8 for delineating maximum extent of the 2013 Colorado front range flood. Remote Sens. 2015, 7, 9822-9843. [CrossRef]

39. Goffi, A.; Stroppiana, D.; Brivio, P.A.; Bordogna, G.; Boschetti, M. Towards an automated approach to map flooded areas from Sentinel-2 MSI data and soft integration of water spectral features. Int. J. Appl. Earth Obs. Geoinf. 2020, 84, 101951. [CrossRef]

40. McFeeters, S. The use of the Normalized Difference Water Index (NDWI) in the delineation of open water features. Int. J. Remote Sens. 1996, 17, 1425-1432. [CrossRef]

41. Xu, H. Modification of normalised differrence water index (NDWI) to enhance open water features in remotely sensed imagery. Int. J. Remote Sens. 2006, 27, 3025-3033. [CrossRef]

42. Shen, L.; Li, C. Water Body Extraction from Landsat ETM+ Imagery Using Adaboost Algorithm. In Proceedings of 18th International Conference on Geoinformatics 2010, Beijing, China, 18-20 June 2010; pp. 1-4.

43. Fisher, A.; Flood, N.; Danaher, T. Comparing Landsat water index methods for automated water classification in eastern Australia. Remote Sens. Environ. 2016, 175, 167-182. [CrossRef]

44. Schumann, G.; Bates, P.D.; Horritt, M.S.; Matgen, P.; Pappenberger, F. Progress in integration of remote sensing-derived flood extent and stage data and hydraulic models. Rev. Geophys. 2009, 47. [CrossRef]

45. Arnell, N. Flood insurance. Floods 2000, 1, 412-424.

46. Brown, K.M.; Hambidge, C.H.; Brownett, J.M. Progress in operational flood mapping using satellite synthetic aperture radar (SAR) and airborne light detection and ranging (LiDAR) data. Prog. Phys. Geogr. 2016, 40, 196-214. [CrossRef]

47. Dasgupta, A.; Grimaldi, S.; Ramsankaran, R.A.A.J.; Pauwels, V.R.; Walker, J.P.; Chini, M.; Matgen, P. Flood mapping using synthetic aperture radar sensors from local to global scales. In Global Flood Hazard: Applications in Modeling, Mapping, and Forecasting; John Wiley \& Sons: Hoboken, NJ, USA, 2018; pp. 55-77. Available online: https: //agupubs.onlinelibrary.wiley.com/doi/10.1002/9781119217886.ch4 (accessed on 27 November 2019). [CrossRef]

48. Pritchard, M.E.; Yun, S.H. Satellite Radar Imaging and Its Application to Natural Hazards. In Natural Hazards; Singh, R., Bartlett, D., Eds.; CRC Press: Boca Raton, FL, USA, 2018; pp. 95-114. 
49. Clement, M.A.; Kilsby, C.G.; Moore, P. Multi-temporal synthetic aperture radar flood mapping using change detection. J. Flood Risk Manag. 2018, 11, 152-168. [CrossRef]

50. Erena, M.; Domínguez, J.A.; Aguado-Giménez, F.; Soria, J.; García-Galiano, S. Monitoring Coastal Lagoon Water Quality through Remote Sensing: The Mar Menor as a Case Study. Water 2019, 11, 1468. [CrossRef]

(C) 2019 by the authors. Licensee MDPI, Basel, Switzerland. This article is an open access article distributed under the terms and conditions of the Creative Commons Attribution (CC BY) license (http://creativecommons.org/licenses/by/4.0/). 